\title{
MOTIVAÇÃO DOS RECURSOS HUMANOS EM BIBLIOTECAS UNIVERSITÁRIAS
}

\section{Rejane Maria Rosa Ribeiro}

\section{Resumo:}

Aborda sobre motivação no campo organizacional, descrevendo sucintamente as teorias motivacionais mais conhecidas, dando ênfase a Teoria das Necessidades de Maslow e a Teoria dos Fatores Higiênicos e Motivacionais de Herzberg, pois as mesmas são voltadas para motivação no trabalho. Descreve os passos para motivar os recursos humanos em bibliotecas universitárias que são: comunicação eficiente, busca de soluções de problemas, reconhecimento e valorização da equipe, delegar responsabilidades e estimular as iniciativas. Apresenta o método proposto por Nicholson para motivar pessoas apáticas ou intransigentes.

\section{Palavras-chave:}

Motivação; Teorias Motivacionais; Bibliotecas Universitárias

\section{MOTIVATION OF HUMAN RESOURCES IN COLLEGE LIBRARIES}

\begin{abstract}
:
It refers to motivation in the organizational environment, describing briefly the most wellknown motivational theories, giving emphasis to the Theory of Needs by Maslow and the Theory of the Hygienic and Motivational factors by Herberg, since these theories discuss motivation at work. It describes the steps to motivate human resources in college libraries: effective communication, how to solve problems, recognition of the team's importance and efficiency, to delegate responsibilities and stimulate initiatives. It presents the method proposed by Nicholson to motivate apathetic or intransigent people.
\end{abstract}

\section{Key words:}

Motivation; Motivational theories; College libraries. 


\section{INTRODUÇÃO}

A motivação no campo organizacional tem sido alvo de estudo por muitos pesquisadores, talvez como tentativa de compreender e solucionar os problemas de trato dos gestores com os recursos humanos nas instituições. Esse relacionamento gestor $\mathrm{x}$ funcionário é o que leva em muitos casos a aumentar as falhas do gestor no seu objetivo de maximizar a eficácia, pois, esses dominam as técnicas de gestão, contudo precisam “[...] entender as pessoas, a principal matéria-prima com que lida diariamente, não só como indivíduos que são, mas também como grupo, já que, afinal, o trabalho é levado a efeito coletivamente" (BERNARDES, 1992, p. 14 ).

A literatura relata muitos estudos sobre motivação no trabalho, mas segundo Oliveira (1997) o mesmo não acontece em relação à motivação dos recursos humanos em bibliotecas, o que obriga os gestores de unidades de informação (bibliotecas) a recorrerem às técnicas utilizadas pela psicologia organizacional e administração de empresas para lidar com seu pessoal.

Os gestores de bibliotecas universitárias, na maioria das bibliotecas, são bibliotecários que por falha nos currículos de graduação possuem pouco conhecimento sobre gestão, desconhecem os estilos de administração e conseqüentemente não sabem como lidar com problemas referentes aos funcionários. Esses gestores necessitam de capacitação em recursos humanos bem como conhecer as teorias motivacionais.

\section{TEORIAS MOTIVACIONAIS}

Muitas são as teorias que abordam os motivos que levam as pessoas a realizarem uma ação. As mais conhecidas são as seguintes:

Teorias Cognitivas - são as teorias que pressupõem o homem como ser racional, com valores, capaz de controlar sua vontade e conseqüentemente responsável por suas ações.

Hedonismo e motivação - nessa teoria acredita-se que as pessoas buscam o prazer e conseqüentemente afastam-se do sofrimento. 
Behavioristas - os behavioristas acreditam que existe uma relação entre o comportamento de uma pessoa em determinado momento e os acontecimentos ocorridos no passado. A abordagem é histórica, o que motiva o comportamento são conseqüências de recompensas ou punições recebidas no passado (AGUIAR, 1984, p. 143).

Teorias do Instinto - defendidas por psicólogos como Freud, McDougal e William James, onde acreditam que os motivos que são herdados determinam o comportamento humano.

Teoria do Impulso - "Propõe a personalidade como um reduto de forças básicas ou energia própria que orienta o comportamento numa ou noutra direção" (BERGAMINI, 1990, p. 114).

Teorias das Necessidades de Maslow - as necessidades constituem a causa de motivação das pessoas e essas necessidades podem ser amor, segurança, auto-estima, realização, estética e fisiológica.

Teoria dos Fatores Higiênicos e Motivacionais de Herzberg - dividida em dois grupos de fatores: satisfação no trabalho (fatores higiênicos) que depende das condições de trabalho tais como o reconhecimento, realização, responsabilidade, etc. E no segundo grupo encontra-se a motivação no trabalho, fatores relacionados com a tarefa o que influencia a produtividade das pessoas.

A importância em conhecer as teorias motivacionais está no fato de que para se conhecer a motivação no trabalho é necessário se conhecer as causas pelas quais o organismo é ativado, quais as condições que determinam a motivação.

Entre essas teorias motivacionais as teorias voltadas para motivação no trabalho mais conhecidas são as Teorias das Necessidades de Maslow e a Teoria dos Fatores Higiênicos e Motivacionais de Herzberg.

\section{MOTIVAÇÃO NO TRABALHO}


As pesquisas sobre comportamento humano mostram que diferentes necessidades estimulam e entusiasmam as pessoas para o trabalho. Essas necessidades ou estímulos foram divididos por Maslow em cinco grupos: necessidades psicológicas definidas como contato humano, proteção, alimentação, sexo, enfim as necessidades intrínsecas do individuo, no segundo grupo ficou a segurança, em seguida as necessidades sociais, o contato entre as pessoas, seguido da estima, ou seja, a necessidade de reconhecimento e aprovação por parte de outras pessoas e como quinto e último grupo, a realização.

É importante a hierarquia de Maslow no ambiente de trabalho, pois evidencia que as pessoas precisam de respeito e reconhecimento, não apenas de dinheiro e recompensa (HELLER, 1999, p. 8).

Para a teoria dos fatores higiênicos e motivacionais de Herzberg as necessidades básicas, elementares ou higiênicas no trabalho não são motivadoras, entretanto causam insatisfação quando não atendidas. Essas necessidades básicas podem ser definidas como: salário, benefícios, as condições de trabalho, o status na empresa, a segurança no trabalho, o grau de controle exercido pelo profissional sobre o trabalho, as relações com os colegas no ambiente de trabalho e a vida pessoal (HELLER, 1999).

Essas necessidades básicas devem ser atendidas, contudo satisfazer só as necessidades básicas não é suficiente. Para que um indivíduo realize um bom trabalho é preciso fatores motivadores que o estimule. Segundo Herzberg apud Aguiar (1984, p. 149) os fatores motivacionais são a liberdade, a responsabilidade, criatividade e inovação no trabalho. Heller (1999) completa os fatores motivadores com as conquistas e avanços, o interesse e o reconhecimento.

Maslow e Herzberg enfatizam a realização como fator principal da motivação no trabalho, McGregor com sua teoria x e y, coloca como objetivo da motivação a auto-realização. Essas teorias contradizem as de Taylor e Fayol que colocam os motivos financeiros como os principais motivadores do trabalho (LOPES, 1980). 
Os gestores devem captar dessas teorias o que cada uma pode oferecer de positivo e usar esses pontos positivos para motivar sua equipe.

\section{MOTIVANDO OS RECURSOS HUMANOS EM BIBLIOTECAS UNIVERSITÁRIAS}

A biblioteca universitária tem como principal objetivo satisfazer as necessidades informacionais de seus usuários, para tanto é necessário que as bibliotecas estejam bem organizadas, com seu acervo atualizado, que ofereçam serviços e produtos levando em conta a segmentação dos clientes (alunos de graduação e pós-graduação, professores, funcionários e pesquisadores) e que nesses serviços e produtos ocorram mudanças e inovações, pois neste novo milênio o mundo está condicionado pela continuidade nas mudanças.

Para atingir seu objetivo as bibliotecas universitárias precisam de seu quadro de pessoal capacitado e motivado para o trabalho.

\footnotetext{
A preocupação é a de que uma biblioteca sem recursos humanos é estática e impotente, basta imaginá-la nos dias em que ela esta fechada. A dinâmica de seu movimento se faz com a presença, a ação e a emoção de seres humanos e da motivação que seus funcionários tem para o trabalho. Um bom desempenho depende de quão motivado estão os funcionários. (OLIVEIRA, 1997).
}

Informalmente sabe-se que as maiores reclamações dos recursos humanos em bibliotecas universitárias são quanto ao salário, realização pessoal, relacionamento interpessoal, benefícios e reconhecimento. Essas reclamações geralmente são ouvidas nos corredores dos Congressos de Biblioteconomia, dos Seminários Nacionais de Bibliotecas Universitárias, dos cursos, palestras e Encontros de Bibliotecários. Pode-se deduzir que, os baixos salários pagos nas bibliotecas universitárias públicas e a falta de benefícios nas mesmas devem-se a pouca valorização da educação e cultura no país e como a biblioteca está diretamente ligada à educação e a cultura sente os reflexos dessa pouca valorização.

Herzberg (2003) enfatiza que a gestão da empresa, supervisão, relações interpessoais, condições de trabalho, salário, status e segurança no emprego são fatores que levam a insatisfação no trabalho. Alguns desses fatores são iguais aos reclamados pelos 
bibliotecários de universidades públicas. E como sanar com as insatisfações? Como motivar? De acordo com Herzberg (2003) isto deve ser feito através do reconhecimento por realizações, do trabalho em si, responsabilidades e crescimento ou progresso. É inegável a contribuição de Frederick Herberg para motivação no trabalho, contudo quais são os passos para motivar o quadro de pessoal de bibliotecas universitárias? Algumas sugestões:

- Comunicação/informação - uma boa parte das bibliotecas universitárias oferece um serviço denominado Disseminação Seletiva da Informação, onde informação a respeito de assuntos específicos é transmitida a usuários específicos, as bibliotecas disseminam a informação com seus usuários e esquecem de disseminar com sua equipe. Conforme Heller (1999, p. 20) "No que se refere à comunicação, a situação ideal é todos saberem a respeito do que afeta direta ou indiretamente, em detalhes e de modo completo, o mais rápido possível”.

Diversos meios podem ser utilizados para desenvolver uma comunicação eficiente, tais como o uso da informática (a INTRANET é muito eficiente para circular informações dentro de uma instituição), as revistas e boletins internos, os murais e o marketing interno.

A importância de que a informação seja passada para toda a equipe é devido ao fato de que nem todo conhecimento ou responsabilidade de decisão se assenta no topo da empresa;

- Buscar soluções - pode ser entendido como não perseguir erros, os motivos dos fracassos devem ser discutidos, avaliados, considerados como uma fonte de aprendizagem, com isso se evita a cultura da culpa;

- Reconhecimento/valorização da equipe - algumas ações simples podem contribuir para que a equipe se sinta valorizada, o elogio de preferência por escrito, discutir e considerar as sugestões dadas pela equipe, promover reuniões onde todos possam expressar suas idéias, apresentar nos eventos, aos visitantes, etc. os componentes da equipe como colaboradores e não apenas como funcionários; 
- Delegar responsabilidades - os gestores centralizadores correm um grande risco de desmotivar sua equipe, é fundamental delegar responsabilidades, com isso a equipe vai se sentir segura, importante;

- Estimular iniciativas - ser receptivo a todas as idéias é claro que algumas serão eliminadas e outras adaptadas ou reformuladas, mas isso deve ser feito em equipe.

\section{MOTIVANDO PESSOAS DIFÍCEIS}

Motivar uma pessoa que deseja ser motivada é uma tarefa árdua, porém gratificante, entretanto motivar pessoas que não querem ser motivadas, pessoas apáticas ou intratáveis isto sim é uma tarefa muito difícil. Segundo Nicholson (2003) a motivação dessas pessoas deve partir delas próprias, o gestor deve utilizar a estratégia de tirar dessas pessoas as soluções. Sendo assim o gerente deve compor uma imagem rica do subordinado, isto é, levantar dados ou fatores que sejam a causa da desmotivação. Em seguida deve ser flexível para reformular metas que sejam viáveis ao funcionário, metas que ele possa cumprir e por fim convidar essa pessoa para uma conversa franca, aberta e em lugar neutro.

Esse método proposto por Nicholson para motivar pessoas difíceis tem a vantagem de inspirar confiança em toda a equipe, pois esta sente que as pessoas difíceis não serão descartadas e sim trabalhadas para mudar de atitude e contribuir com a equipe.

Pessoas intransigentes são encontradas em todas as instituições porém são um grande problema em bibliotecas onde quase todos os serviços são voltados ao público. Se um usuário for atendido por uma pessoa mal-humorada, apática ou desinteressada esse usuário vai formar uma imagem negativa daquela biblioteca, ele vai repassar para várias pessoas aquela imagem comprometendo todo o trabalho desenvolvido pela biblioteca. 


\section{CONSIDERAÇÕES FINAIS}

O esforço não acaba após motivar a equipe, é necessário manter a motivação em alta. De acordo com Heller (1999, p. 64) isto é possível dando variedades às condições de trabalho, melhorando o sistema de gerenciamento e atribuindo grande valor aos colaboradores.

As bibliotecas universitárias precisam ficar atentas. Se objetivam oferecer bons serviços, conquistar, cativar e manter usuários é necessário ter seus recursos humanos capacitados, motivados e não poupar esforços para manter em alta essa motivação.

\section{REFERÊNCIAS}

AGUIAR, M. A. F. de. Psicologia aplicada à administração: uma introdução à psicologia organizacional. São Paulo: Atlas, 1984.

BERGAMINI, C. W. Psicologia aplicada à administração de empresas: psicologia do comportamento organizacional. 3. ed. São Paulo: Atlas, 1990.

BERNARDES, C. Sociologia aplicada à administração: o comportamento organizacional. 3. ed. São Paulo: Atlas, 1992.

HELlER, R. Como motivar pessoas. São Paulo: PUBLIFOLHA, 1999. (Serie sucesso profissional: seu guia de estratégia pessoal).

HERZBERG, F. Uma vez mais? Como motivar os funcionários. O melhor da HBR 1968. Harvard Business Review, v. 8, n. 1, p. 59-68, jan. 2003.

LOPES, T. de V. M. Motivação no trabalho. Rio de Janeiro: FGV, 1980.

NICHOLSON, N. Como motivar os problemáticos. Harvard Business Review, v. 8, n. 1, p. 39-47, jan. 2003.

OLIVEIRA, S. M. M. de. Índice de satisfação e motivação dos recursos humanos de uma biblioteca universitária: um instrumento para administradores. In. CONGRESSO BRASILEIRO DE BIBLIOTECONOMIA E DOCUMENTACAO, 18., 1997, São Luiz. Anais... São Luiz: COLLECTA/APBEM, 1997. Disquete 3. 


\section{REJANE MARIA ROSA RIBEIRO}

Aluna do Curso de Acesso ao Mestrado em Gestão da European University

Especialista em Bibliotecas Universitárias - PUC - MG

Especialista em Metodologia do Ensino Superior - UEFS

Bibliotecária - Diretora do Sistema de Bibliotecas da UEFS

Universidade Estadual de Feira de Santana

Km 13, BR 116 - Campus Universitário

Feira de Santana - Bahia

E-mail: rribeiro@uefs.br

Artigo aceito para publicação em: 01/05/2004 